Stress and Stress Management in European Crisis Managers

Mirjam Haus, Christine Adler, Maria Hagl, Markos Maragkos

Ludwig-Maximilians-Universität München, Germany

Stefan Duschek

UMIT - University of Health Sciences, Medical Informatics and Technology, Hall, Austria

Author Note

Mirjam Haus, Christine Adler, Maria Hagl, and Markos Maragkos, Department of Psychology, Ludwig-Maximilians-Universität München, Germany; Stefan Duschek, Institute of Applied Psychology, UMIT - University of Health Sciences, Medical Informatics and Technology, Hall, Austria.

This article was published in: Haus, M., Adler, C., Hagl, M., Maragkos, M., \& Duschek, S. (2016). Stress and stress management in European crisis managers. International Journal of Emergency Services 5(1), 1-17. (DOI 10.1108/IJES-12-2015-0026)

This project has received funding from the European Union's Seventh Framework Programme for research, technological development, and demonstration under grant agreement no 312395 . We are deeply grateful to the crisis managers who participated in this study. Furthermore, we would like to thank Stanislav Metodiev for his contribution in coding the interview data and our project partners for conducting the interviews. Correspondence 
concerning this article should be addressed to Mirjam Haus, Department of Psychology, LudwigMaximilians-Universität München, Leopoldstr. 13, 80802 Munich, Germany.

E-mail: Mirjam.Haus@psy.lmu.de 


\section{Stress and Stress Management in European Crisis Managers}

\section{Stress and leadership in crisis management - Target group: crisis managers}

When a disaster strikes, all units involved have to consolidate their efforts to ensure a comprehensive and effective disaster management. While the majority of research addresses the work environment and stress of first responders such as fire and rescue workers, only few studies place an additional focus on the specific stressors and stress management strategies of crisis managers $^{[1]}$ (i.e., crisis management leaders; Brown \& Campbell, 1990; Kirkcaldy, Brown, \& Cooper, 1998; LaFauci-Schutt \& Marotta, 2011; Regehr \& Bober, 2005).

Disasters are defined as incidents with a low probability of occurrence but a high impact for the affected population, helpers, and crisis management professionals. They usually overwhelm local crisis management resources, threaten the well-being, health and (the sense of) security of the public, and cause severe infrastructural and financial damages (adapted from Hadley et al., 2011). During disasters, there is a significant need for effective leadership (Pillai \& Williams, 2004). Crisis leadership can be defined as "[...] the process of leading group members through a sudden and largely unanticipated, intensely negative, and emotionally draining circumstance" (DuBrin, 2013, p. 3). The duties and responsibilities of crisis managers in the scope of a disaster include risk and information assessment, judgment and decision making, provision and distribution of personnel and aid/psycho-social support supplies, mobilizing and coordinating first responders, leading and supporting subordinates, as well as identification of immediate needs of the affected community.

Successful crisis managers are expected to have experience in working under pressure, to be prepared for crises, to take responsibility, to have a realistic confidence in their own abilities, 
to remain focused, and to adapt to changing conditions (Adams, Dust, \& Piccolo, 2013).

Furthermore, self-management, individual responsibility, and skills in coping with stress in crises situations are seen as key competencies (Ungerer \& Morgenroth, 2001).

\section{Stressors and coping in crisis management}

As one of the most common models of work-related stress, the demand-control-support model by Karasek and Theorell (1990) was considered in examining the work environment of crisis managers in this study. The model focuses on three aspects/dimensions that characterize psychosocial work environments: work-related physical and psychological demands, possibilities for control, and received support from co-workers and supervisors. It postulates that a balance of the three dimensions will increase job satisfaction whereas an imbalance (experiencing high levels of demands, while having few possibilities for control and receiving few support ) may lead to stress and strain. The model has been previously applied in crisis and emergency management research; Regehr and Millar (2007) reported in their mixed-methods study that paramedics experienced their work environment as being high in demand and low in control and support.

Crisis management personnel are at elevated risk to suffer from physical and mental health consequences of work-related stress and traumatic incidents such as posttraumatic stress disorder (PTSD), depression, anxiety, and burnout (e.g., Alexander \& Klein, 2001; Bennett, Williams, Page, Hood, \& Woollard, 2004). As several researchers have pointed out, occupational (e.g., time pressure, conflicting roles) and organizational stressors (e.g., team conflicts) have a considerable impact on the health and well-being of crisis and emergency management personnel; they are often perceived as more stressful than event-specific/critical incident stressors (Brown \& Campbell, 1990; Regehr \& Bober, 2005) or even better predictors for 
psychological distress (Liberman et al., 2002). According to Regehr and Bober (2005), stressors and stress levels differ depending on the positions/ranks of crisis management personnel within the organization, indicating that chiefs, executives and supervisors are likely to experience the highest levels of work-related stress (see also Kirkcaldy et al., 1998). Crisis managers are usually involved in daily routines within their workplace environment when they abruptly need to take action in the face of a disaster. In this context, it is assumed that ongoing concerns and organizational stressors form the basis to which critical incidents are added and might undermine resources for dealing with major incidents (Liberman et. al, 2002; Regehr \& Bober, 2005). While crisis managers might be less often directly exposed to potentially traumatic stressors than first responders (depending whether they work in an executive position on-site or in a strategic position off-site), their positions imply a particularly high level of decision-making and managerial responsibility (Hadley et al, 2011). This encompasses resources like more decision latitude but also additional stressors like higher responsibility for people and lives, and farreaching and non-foreseeable consequences of failures.

Regarding stress management and coping in crisis and emergency management, research comes to conflicting results. Most studies indicate that avoidance-oriented coping styles are associated with greater (physiological) distress (e.g., LeBlanc et al., 2011) and the development of posttraumatic stress symptoms (e.g., Brown, Mulhern, \& Joseph, 2002). Problem-focused coping styles have mostly been shown to be associated with greater mental health, whereas emotion-focused coping tends to be associated with increased distress and related health symptoms (e.g., LeBlanc et al., 2011). However, some studies report distinct findings; Patterson (2003), for instance, found that emotion-focused coping buffered the relationship between critical life events and distress in police officers, whereas problem-focused coping increased 
distress in the context of critical work events. Overall, coping research suggests that the overall pattern of coping styles may be more predictive of mental health than the use of any particular strategy (Aldwin, 2007).

Research about preventive stress management trainings for emergency personnel is scarce (see Varker \& Devilly, 2012). The majority of stress management programs stem from the field of law enforcement (with no measurable success according to the meta-analysis of Patterson, Chung, and Swan, 2012) and military psychology. Literature research shows that there are no evaluated stress management programs targeting crisis managers. One of the main objectives of the EU-FP7-funded project PsyCris (PSYcho-social support in CRISis management) is to develop interventions to support crisis managers in dealing with stress and to prevent stress-related disorders. As a first step, particular stressors, perceived stress, and applied stress management/coping techniques in crisis management were examined. Following an exploratory, qualitative approach, crisis managers were interviewed in depth for shedding light on the following research questions:

1. What are the most demanding stressors experienced by crisis managers?

2. How do crisis managers perceive their work environment concerning the dimensions demands, control and support?

3. What kind of stress management techniques/coping methods do they use and/or find helpful? 


\section{Method}

To explore the experiences of crisis managers, 34 semi-structured, guideline-based interviews were conducted in five EU countries and then analyzed with the qualitative text analysis method GABEK ${ }^{\circledR}$.

\section{Participants and Procedure}

In the PsyCris project, "crisis managers" are defined as strategic, tactical, and operational managers and supervisors in organizations involved in national or local disaster response and civil protection (like Red Cross, fire brigades, public authorities, agencies for technical relief, the military and psychological/psychosocial crisis intervention institutions). These institutions or organizations are involved in at least one level of psychosocial support, e.g., in the course of protection and rescue, or dissemination of information, organization of psychosocial support, identification of people at risk, or follow-up care and treatment. In their positions, crisis managers - belonging to the middle and higher management - have responsibility for employees and decision making. They may be (permanent or appointed) heads or members of a disaster management unit or incident commanders. As additional criterion for the interviews, the crisis managers should at least have been directly involved in the management of one major crisis or disaster. A convenience sample of eligible crisis managers was recruited by reaching out to crisis management organizations (as described above) in five EU countries via phone and e-mail. The research was approved by the project leading University's respective Ethics Committee and all participants gave written informed consent.

Out of the 34 interviews, 31 were included in the analysis ${ }^{[2]}, 12$ conducted in Germany, 8 in Spain, 4 in Luxembourg, 4 in Lithuania, and 3 in Austria. They were conducted between November 2013 and January 2014. Table 1 shows the socio-demographic information of the 
sample. On average, the interviewees were approximately 51 years old, had nearly 26 years of experience in crisis management and held their current positions since almost 12 years. The majority of the interviewed crisis managers was male; only 6 interviewees were female. Most of the participants were affiliated with rescue and emergency (medical) services, fire services and specialized institutions for psychosocial support and crisis intervention, only four were from public authorities and two had a military background. When focusing on a disaster operation they were involved in, the interviewees referred either to major flooding that had occurred throughout Europe, or to mass casualty incidents such as airplane crashes or terrorist attacks.

Table 1. Socio-demographic data of the interviewed crisis managers $(\mathrm{N}=31)$

Characteristic

Sample

$(N=31)$

\begin{tabular}{|c|c|c|}
\hline \multicolumn{3}{|l|}{ Gender } \\
\hline Female & 6 & $(19 \%)$ \\
\hline Male & 25 & $(81 \%)$ \\
\hline Age $M(S D)$ & 50.90 & $(8.32)$ \\
\hline Work experience in years $M(S D)$ & 25.71 & $(10.51)$ \\
\hline Work experience in the current position in years $M(S D)$ & 11.86 & $(8.32)$ \\
\hline \multicolumn{3}{|l|}{ Current position } \\
\hline Paid & 23 & $(74 \%)$ \\
\hline Voluntary & 5 & $(16 \%)$ \\
\hline Paid + voluntary & 3 & $(10 \%)$ \\
\hline
\end{tabular}


The interviewers were trained in interview techniques and the developed interview guideline. After completing a socio-demographic questionnaire, the participants were interviewed (30-60 minutes) at their workplace or at the offices of the interviewers. All interviews were audio recorded. The audio files were then transcribed and translated either into English or German.

\section{Data Collection and Analysis}

The applied interview guideline, which primarily reflected the three research questions named above, addressed, among others, the topics work environment in crisis management, experienced stressors (demands), and stress management techniques as well as perceived control in crisis situations, and (organizational) support. For the analyses only the parts of the semistructured interviews that targeted these domains were used, focusing on stress and stress management, together with examining the data from the angle of the demand-control-support model (see above).

The interviews were analyzed with the method GABEK ${ }^{\circledR}$ (GAnzheitliche BEwältigung von Komplexität, i.e., holistic processing of complexity; Zelger, 2004). GABEK® is a tool for analyzing qualitative data that links statements of different surveyed persons by filtering out the common key messages. The experiences, opinions, and knowledge reported by interviewees are transformed via GABEK $\AA$ and the corresponding software WinRelan ${ }^{\circledR}$ (Winword Relation Analysis; Zelger, 2014) to conceptual knowledge systems, e.g., in forms of networks of connected key terms.

Data analysis with GABEK $®$ WinRelan ${ }^{\circledR}$ is a structured and rule-based process consisting of different steps. At first, the transcribed interviews were segmented in "sense units" (short text sections with related content and thoughts, e.g., a spoken sentence; in total 2,453). Subsequently, in each text section three to nine meaningful "key terms" (in total 2,259) were 
marked by two trained coders (one of them being the first author). These key terms are relevant lexical terms with an individual semantical meaning that define the central message of the respective text section. The coding stayed as close as possible to the original data, meaning that mostly the interviewees' own words were marked as key terms. The coding decisions of the analyzing researcher can be retraced at any time by checking the respective text sections.

To display the content of the interviews relevant for the research questions, network graphs (i.e., networks of connected key terms) were used. For each of these, one initial key term of interest (i.e., one of the predefined variables of interest; stress, demand, control, support, and stress management) was chosen as basis of the graph. In order to obtain sufficiently clear and interpretable network graphs, the software WinRelan ${ }^{\circledR}$ enables the user to determine a minimum number of connections for each network graph. The automatically generated graphs show all key terms (and their connections) that were mentioned in combination with the initial key term at least as often as the previously chosen minimum. Thereby, relevant aspects of a topic can be displayed and their connections can be examined. The minimum number of connections in each network graph should be determined in a way that sufficient readability is ensured, without compromising important aspects. Given the different prominence of topics (e.g., stress as main topic of the interviews), the chosen minimum varied across the different graphs. Thus, for the main constructs which were particularly frequently mentioned across the interviews (e.g., stress, 249 times), the determined minimum number of connections had to be comparably high (in this case: 12) to ensure readability. To support the interpretation of the connections within the network graphs, the original statements that form the basis of the connection between two key terms can be selectively checked by the user in WinRelan $\AA$. This feature was used to choose representative sense units (i.e., quotes) that explain and underpin the connections shown in the 
graphs. Beyond that, for the purpose of an easier reading and to highlight the semantical background of the connections, categories of key terms were built that are displayed in the graphs by means of different shapes.

\section{Results}

\section{Stress}

To analyze the perceived stress and stressors experienced by the interviewed crisis managers in the context of disaster operations (see research question 1), a network graph based on the key term stress and the underlying statements respectively connected text sections were examined (see Figure 1). The graph shows the connections between terms that were frequently mentioned (12 times or more) in combination with the term stress.

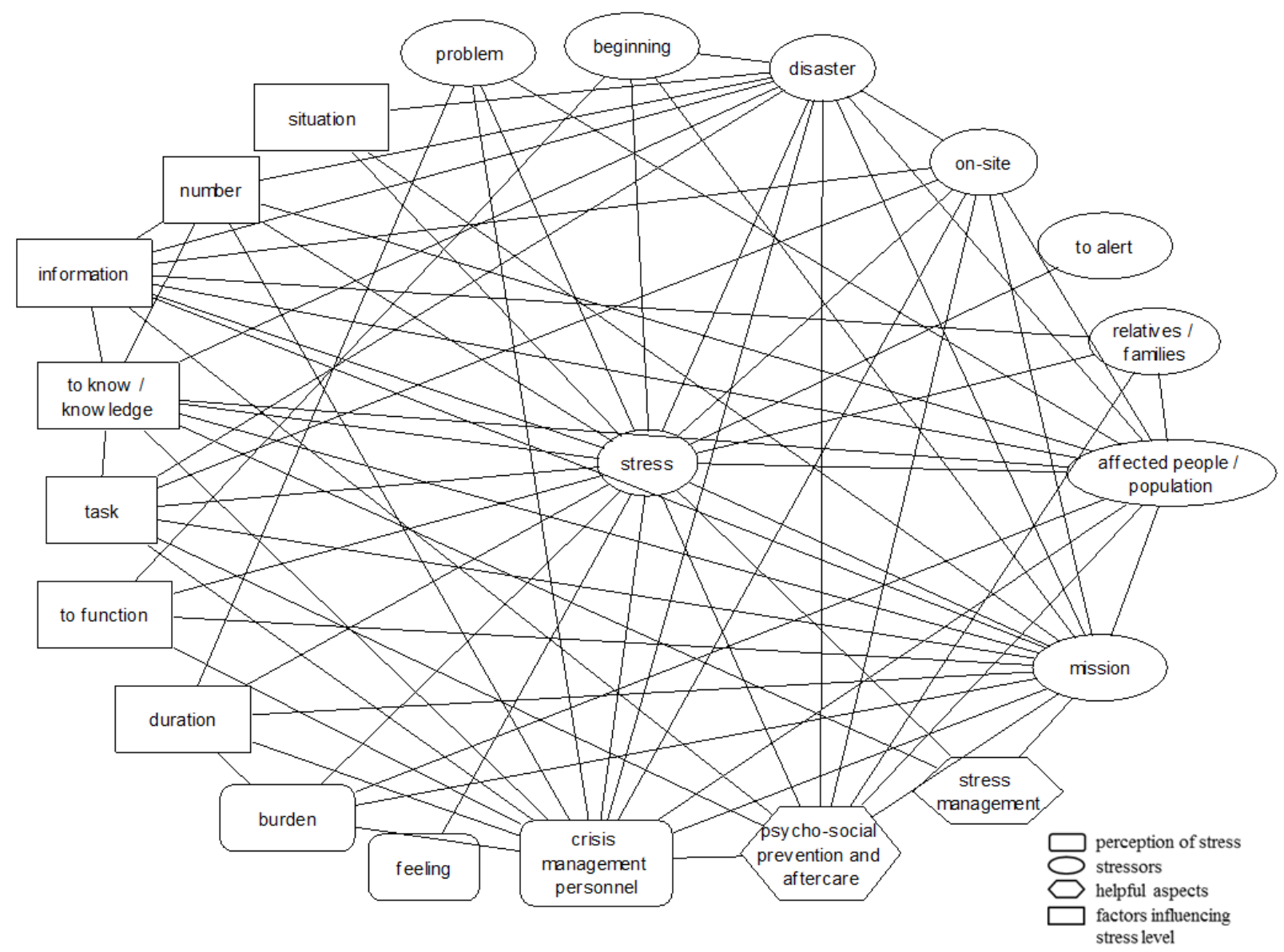

Figure 1. Network graph "stress" 
Within the network graph, the terms associated with the initial key term stress are strongly cross-linked in a complex way. This indicates that the stress experienced by the interviewees in the context of crisis management is not caused by isolated stressors but by an interaction of stressors (e.g., dealing with affected persons), environmental conditions (e.g., duration) and individual factors (e.g., knowledge) as well as resources (e.g., stress management techniques).

Overall, the interviewees associated stress repeatedly with emotions and the perception of burden, experienced by themselves and their colleagues (crisis management personnel); key terms describing the perception of stress presented in rounded rectangles. Apart from the expectably related key terms, disaster and mission, specific stressors frequently reported by the crisis managers were dealing with affected persons, relatives and families, problems arising during the mission and the situation on-site (stressors presented in ellipses).

Besides the stress related to bearing responsibility for the affected people, relatives and families, living up to subordinated crisis management personnel - which is an additional important and challenging responsibility inherent to the supervising positions of crisis managers - was also mentioned in this context:

"It's such a challenge that you would lie when saying that you weren't under a great deal of pressure [stress] ${ }^{[3]}$ during this time [crisis mission]. And you must imagine that you must live up to so many things, your own staff [crisis management personnel], the affected people, the government, the media (...)" $[\mathrm{Je} 7]^{[4]}$

Concerning the different phases of a disaster, the highest levels of stress were perceived in the beginning of the disaster operation (reflected by the connection between stress and beginning), shortly before and after a disaster alert was given. During the disaster operation 
itself, the crisis managers frequently reported concentrating on working without consciously perceiving stress. After the mission, when crisis managers had time to think about the incident, stress was likely to return:

"But, as said, the amount of stress was quite high in the beginning, uncannily high, because we were just a few people and what was asked from us was enormous, because we also put ourselves under pressure, that's for sure." [Fw9]

"If I had to assess the level of stress, I think most stress is caused by the initial sense of unetint:" KR

"During the mission people hardly ever have stress. That happens later, maybe when they relax. (...)" [Ho8]

Aspects that influenced the level of stress experienced by the crisis managers were the kind of tasks and duties, the extent of available information and knowledge, the duration of the mission and the number of affected people (influencing factors presented in angular rectangles). "One thing is not knowing how many people are at risk and another is knowing that 50 or 100 people are in danger. It's still stressful [...]. The next step is to deal with the most critical situations in the shortest time possible." [Ke7]

Examining the statements (i.e., sense units) underlying the connection between task and stress, specific tasks and duties causing stress during the disaster operation were identified. In this context, the crisis managers experienced the communication with press and media, direct victim contact, high responsibility (for far-reaching decisions to be made under time pressure) and having to answer for potential failures as particularly stressful: 
"And then you must function properly, that is you must make the right decisions, within the shortest period of time, because you have a huge responsibility then, and then the stress is extremely high." [Fw6]

"[Stress] And the press is a bit of a problem, that I must say as well. I am well aware of this sensationalized tabloid press and everything, but it's nearly impossible to handle this (...) $"[A x 8]$

“(...) And that is, I think, what burdens many. This hostility, 'why this way and not differently'. You have to decide on short notice in this situation, and I think, for making decisions in this situation, one must consider that we are under pressure." [Bc4] Concerning the mitigation of stress effects, stress management and psychosocial prevention and aftercare (provided for victims, families and crisis management personnel) were frequently mentioned by the interviewees (helpful aspects presented in hexagons). Furthermore, barriers to make use of psychosocial support opportunities were addressed in this context: “(...) There was the offer [psychosocial support], but not everyone made use of it, since we all are broad-shouldered and we do not always admit that we have problems." [Fv3]

\section{Demand, Control, and Support}

The stress experienced by crisis managers was further analyzed by examining the dimensions perceived demands, possibilities for control and received support related to their work environment (drawing on the model of Karasek and Theorell, 1990; see research question 2). For this purpose, the three network graphs (with the initial key terms demand, control, and support $^{[5]}$ ) and the respective underlying text sections were examined (graphs not shown; the minimum number of connections between the key terms being 5 for demand and control and 8 for support). 
During crisis management and disaster operations, crisis managers reported to be confronted with high demands and challenges, which pushed them to their limits and required high levels of skills to be able to deal with them:

“(...) I'd say that the ten days were continuously stressful: High demands that we were just able to manage. You always wonder about yourself, how this actually worked, physically, how you were able to go through with it." [Eo6]

Concerning particularly demanding aspects, the crisis managers described a long duration of the disaster operation, difficult cases of taking care of affected persons (as during evacuations), the need to react as fast as possible as well as the coordination of psychosocial support, of personnel, and volunteers. Beyond that, the change from daily work and day-to-day occupational structures to the implementation of disaster control structures was experienced as demanding.

"The first day, all of us did not sleep. That was a challenge. Those people [affected persons] had to be evacuated; our people [crisis management personnel] worked around thclkw hqiqme" [6]

"What I consider a difficulty and a challenge, but also a point that one needs to seriously address in the future, is the coordination of everything (...)” [Bq9] “(...) Of course, the acute phase was very chaotic because there was no structure in place yet, meaning the structure that is needed in addition to the existing structure for day-to-day missions. This was quite a challenge for everybody during the first week." [Aa4]

Concerning control during disaster operations, the interviewees addressed limited possibilities to fully control the situation. The perceived lack of control was reported to cause 
stress and was rather experienced in the beginning of disaster operations, depending on the scale of the disaster.

"Yes, that's always like that, when things abruptly run out of control... That's [crisis situation] something difficult to control directly. Honestly, that's because we do not have much experience with missions of this scale (...)" [Gh5]

"I perceive situations as stressful when I cannot control them, unrelated to the fact whether I really cannot control them or whether I just realize I do not know how to deal with them." [Ax4]

Important aspects for controlling a situation are previous knowledge as well as available information and feedback (particularly concerning the situation on-site). Crisis managers perceived more control in situations when they had enough and competent human resources to manage the crisis.

"I was out there at the fire station in the incident command center and there it's extremely important that you obtain information from the disaster site, and when the information flow does not work with 100 percent, then you are powerless (...)." [Bs4] “(...) Since there is always a lack of information, you cannot control everything, because you do not know everything. For example, when I requested some additional forces, I did not know whether and when I would get them. (...)[D19]

Regarding received and required support during and after crisis missions, the interviewees stated the importance and need of support for reducing stress, depending on the scale of the disaster. In this context, particularly the organization, executives and supervisors as well as colleagues were named as important providers of support. 
“(...) One week after the intervention, they [organization] called me to see how I was doing and to congratulate me for the work I had done. That call is one of the most positive things I remember, not just because they valued my work during the crisis but also because they were concerned about how I was one week after the mission. (...)” [Lg5, Lg6]

"It was an advantage (...) that my closest companions, those who help me manage the unit, were well aware of the pressure I was under and they tried to give me their support." [Kl5]

However, levels of received support differed between the interviewed crisis managers: "In the first phase we are alone anyway, we must be able to function alone, too, but it is certainly a big support to have contact persons for different questions and problems which occur later (...) that one can ask people who are responsible for that. (...) But this was missing back then " [Ga7]

Concerning the crisis managers' role as supervisors in leadership positions, experience and knowledge were described as helpful to effectively support staff and co-workers.

"If there is someone, who has a certain level of experience, the people who work with him are calmer, maybe it changes their way to deal with things. They have the feeling, that someone is there who helps them to reduce the stress." [Gi7]

\section{Stress management}

Finally, a network graph for the term stress management was created to analyze the crisis managers' attitudes and requirements concerning stress management techniques as well as strategies they apply during and after disaster operations (see research question 3). Figure 2 
shows the connections of terms that were frequently mentioned ( 9 times or more) in combination with the key term stress management.

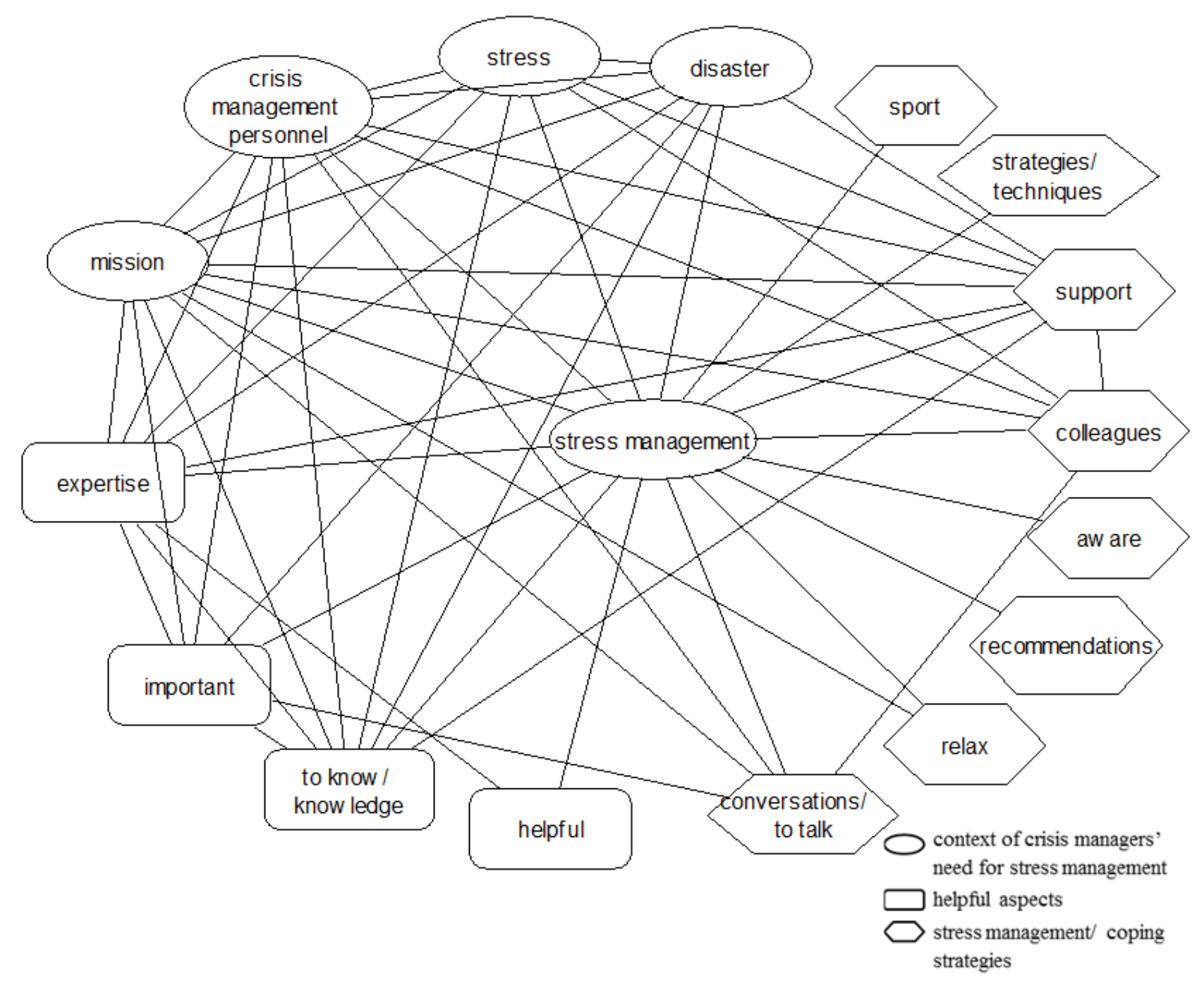

Figure 2. Network graph "stress management"

The crisis managers described a need to competently cope with the high levels of stress related to disaster missions. In this context, they addressed the importance of stress management techniques to effectively manage a disaster (context of crisis managers' need for stress management presented in ellipses).

"[stress management] But you have to act step by step, otherwise you'll end up losing your temper and you won't manage the crisis properly. (...) The experience teaches you 
that you have to keep calm and control yourself because getting nervous and responding inappropriately will get you nowhere." [Ll1, Ll4]

"But what we realized during the mission: Stress management techniques were necessary as there were exhausted helpers who were burdened." [Eh6]

Several crisis managers mentioned that they had not received any stress management training and would not apply any specific strategies; or if they did, they had learned them by themselves:

“[stress management] As far as I know, no one of us has applied something as specific as an autogenic training yet" [Ae9]

"I learned these techniques by trial and error." [Lfl]

Concerning recommendable stress management techniques, the interviewees suggested that everyone should have the opportunity to find out what works best for him- or herself, preferably with the help of training. In this context, they also addressed the importance of recognizing own signs of stress and knowing one's limits.

"I think, everyone has to find out for himself, because I know a lot of colleagues who have completely different strategies, and I believe that I would recommend to someone, who cannot cope with this, to explore different trainings and to think about how these are helpful.(...)” [Bd5]

“(...) As a professional helper you should be able to assess for yourself when the point has come where you need to take a step back and take a deep breath." [Bl8] Regarding applied techniques or strategies to deal with the stress related to a disaster operation (stress management/coping strategies presented in hexagons), the crisis managers described doing sports, retreating from the situation (during breaks), seeking support and talking 
to their families or friends. Further reported techniques and coping strategies were breathing and relaxation techniques, distraction, distancing, socializing and continuing day-to-day activities. Beyond that, seeking support from peers and colleagues was repeatedly mentioned in relation to coping with mission-related stress.

"Especially for me, I must say, it is simply the peace and quiet to get away from it all, to be somewhere at home, to walk the dog, or to do some sports. These are the right things." [Af2]

"The second technique, if we notice a greater sense of anxiety or uncertainty, is to practice breathing and relaxation techniques ... and share our feelings with a colleague who we know is trustworthy and prepared." [Kv5+6]

Aspects that were described as helpful or important in dealing with the stress (helpful aspects presented in rounded rectangles) are knowledge and crisis management expertise.

"Performing exercises, having procedures, knowing and implementing them and knowing whether they work or not, all that helps you." [Ks3]

\section{Discussion and recommendations}

To support crisis managers in dealing with the stress related to the management of disasters, the PsyCris project aims to develop a stress management training program tailored to their specific needs. For this purpose, perceived stressors and demands, perceived levels of control and experienced support as well as stress management strategies of crisis managers were examined in this study by means of guideline-based interviews that were analyzed with a qualitative text analysis method.

Some stressors described by the crisis managers are relevant for first responders as well, like event-specific aspects of the mission (e.g., high number of affected persons, long duration, 
scale/extent), dealing with affected persons and families, problems arising during the mission, and the situation and conditions on-site. In addition, the crisis managers addressed stressors and stressful tasks associated with their leadership position: the issue of communication with press and media, high responsibility for population and staff, far-reaching decisions to be made under time pressure and having to answer for potential failures. These results support the limited number of previous findings regarding stressors of supervisors and leaders in crisis management (e.g., Hadley et al., 2011; Regehr \& Bober, 2005). Following the demand-control-support model of job stress (Karasek \& Theorell, 1990, see above), these three dimensions were given special importance in examining the psychosocial work environment of crisis managers: Overall, the crisis managers reported high demands and challenges during disaster management (e.g., the change from day-to-day occupational structures to disaster control structures, the need to react fast, and coordination issues); some of these reflected the above described stressors, referring to extent and particularly difficult tasks like large-scale evacuations.

Regarding perceived control, the interviewees addressed limited possibilities to fully control the situation during disasters. This lack of control was rather experienced in the beginning of disaster operations, also increasing distress. Concerning aspects that were helpful and important for maintaining a sense of control, the crisis managers mentioned sufficient human resources, (previous) knowledge, up-to-date information and properly functioning communication. Considering that a sense of helplessness has been associated with PTSD in previous studies (Bryant \& Harvey, 1996), it is essential that crisis managers are aware of and prepared for these limited possibilities of control during disaster operations. Focusing on the combination of demands, control, and support, the interviewed crisis managers reported experiencing high levels of demands, limited possibilities of control and varying levels of 
received support. This could be seen as a critical combination of the three dimensions, potentially resulting in stress and adverse health consequences. However, in this study the aspect "control" was assessed in the context of disaster operations, where dealing with uncontrollable situations is deemed, up to a point, part of the task. Because of this focus on disaster operations, control was not operationalized in the sense of decision latitude within organizations as in Karasek and Theorell's (1990) model, so conclusions about the crisis managers' experiences concerning control in their everyday work environment cannot be drawn. Regarding received support, supervisor and organizational support (besides support from peers and colleagues) was reported to be crucial and particularly helpful, similar to findings of Halpern, Gurevich, Schwartz, and Brazeau (2009) in interviews with emergency medical technicians (EMTs) and their supervisors. In line with Karasek's and Theorell's model, it is assumed that this received social support is important in mitigating the effects of the high demands and limited control experienced by the crisis managers.

The interviewees also addressed barriers (experienced by themselves and other kinds of crisis management personnel) to seek support and to participate in psychosocial support measures: above all, the professional and societal role that implies to be strong and stress resistant (see the EMTs' statements in Halpern et al., 2009). This role concept may hinder broaching topics of stress and excessive occupational demands and perpetuates still existing stigmatization of admitting burden and seeking support in crisis management organizations.

Regarding stress management in the face of disaster operations, the crisis managers emphasized their need to competently cope with mission-related stress, also to ensure effective crisis management. However, it was also mentioned that target-oriented stress management trainings are scarce and that specific, previously learned strategies are rarely applied by crisis 
management personnel. In this context, the crisis managers also stated the importance of recognizing own signs of stress and knowing one's limits (see also Halpern et al., 2009). Concerning their strategies to handle mission-related stress, they reported a broad variety of methods, reflecting all kinds of coping styles. They described for instance doing sports, seeking emotional and practical support and appreciation from peers and colleagues, retreating from the situation (e.g. during breaks), or distracting oneself with different activities. However, clear recommendations about which kind of coping strategies to prefer are not reasonable as the effectiveness of a particular coping strategy depends on individual determinants as well as on situational circumstances (Aldwin, 2007). As an example, problem-focused approaches seem to be recommendable whenever at least parts of the situation can be controlled whereas emotionfocused strategies might be more effective to regulate emotions in uncontrollable circumstances or in the aftermath of a disaster (Jensen \& Wrisberg, 2014; Young, Partington, Wetherell, St Clair Gibson, \& Partington, 2014). Consistent with these aspects, the crisis managers interviewed in this study recommended that everyone is given the opportunity to find his or her own effective stress management strategies that may differ during the different disaster phases.

In the following, recommendations derived from the study's findings and from comparisons with previous research and literature are presented. Beyond that, perspectives on how to further support crisis managers with the stress related to their work environment are pointed out.

The mitigation of occupational and organizational stressors experienced by crisis managers in the context of disaster operations is one of the first steps to support this professional group and to facilitate effective crisis management. Crisis management organizations could use this study's findings to check and compare with their individual context which stressors could be 
possibly mitigated or how to ameliorate the working conditions for crisis managers. For instance, concerning distress due to having to deal with the media, respective trainings could be implemented and expanded on new communication forms involving social media.

However, some of the stressors and demands during crisis management lie in the very nature of large-scale missions, and they come with being responsible for managing the disaster response. Therefore it is recommendable to sensitize crisis managers (including next generation) for the specific stressors related to their professional position. For example, reflecting and anticipating the specific demands and challenges in crisis management in the scope of stress management trainings, will enhance preparedness for and predictability of expectable stressors (e.g., a sense of loss of control due to particularly adverse conditions during a mission). This kind of predictability (Thompson, 1981; control through information), in turn, is assumed to increase the level of perceived control and may buffer the distress due to experiencing momentarily feelings of helplessness. For this purpose and in light of the gathered views and experiences of this sample, it is recommendable to include the following aspects in stress management trainings for crisis managers:

- Sensitizing about potential stressors during disaster response and about limited possibilities for control in particular as well as reflecting and fostering functional strategies to cope with the related distress.

- Enhancing coping flexibility, which means not only the variety of the coping repertoire but also the flexibility to assess which coping strategies are applicable in which situation (Cheng \& Cheung, 2005).

- Educating about stress reactions and how to recognize symptoms of stress in oneself and others. 
- Educating about constructive ways of providing support considering the crisis managers' role as supervisors with responsibility for their staff.

- Addressing the (organizational and individual) role concept of crisis managers as well as the existing stigmatization of admitting distress and need of support. Overall, stress management programs should not endanger or weaken the professional role of crisis managers, but trying to de-stigmatize experiencing stress and seeking support.

It is assumed that supporting crisis managers in recognizing their own stressors and signs of stress and in applying functional strategies to deal with them, will help them to lead more effectively in crises situations, to act as role models and to support their staff in dealing with mission-related stress. Within the PsyCris project, the findings of this interview study are used to develop a prototypal stress management training integrated in an Internet-based learning environment for crisis managers that values their experiences and strives to build a "community of practice" (i.e., an expert network; Adler, Sauter, Meyer, Hagl, \& Raich, 2015).

\section{Limitations}

One limitation in this study is the recruitment of participants by reaching out to crisis management organizations, which means that systematic self-selection in some way or the other cannot be ruled out. Thus, the results of this study are not generalizable to the whole population of European crisis managers, but considering the straightforward definition of crisis managers and the inclusion criterion of having practical experience in the management of at least one disaster, they are a first contribution in examining the psychosocial work environment of this occupational subgroup. Altogether, five different countries from all over Europe were included in this study. Therefore, interviews from Spain, Luxembourg, and Lithuania had to be translated 
to render them analyzable. As the analysis with GABEK $\AA$ WinRelan ${ }^{\circledR}$ sets a special focus on the exact wording used by the interviewees, it cannot be ruled out that the translation compromised the validity of the data. However, the risk was minimized by rechecking repeatedly with the respective interviewers and translators. Another limitation is based on the fact that subgroup comparisons (e.g., nationality, gender) were not conducted, due to the small and differing samples sizes of the single subgroups. Examining such differences could be part of further studies. 


\section{References}

Adams, J. B., Dust, S. B., \& Piccolo, R. F. (2013). Approaches to minimize choking under pressure. In A. J. DuBrin (Ed.) Handbook of research on crisis leadership in organizations (23-47). Northampton, MA: Edward Elgar Publishing.

Adler, C., Sauter, W., Meyer, J., Hagl, M., \& Raich, M. (2015). First steps in the development of an internet-based learning platform for strategic crisis managers. Paper presented at the ISCRAM 2015 Conference, Kristiansand. Retrieved from http://iscram2015.uia.no/wpcontent/uploads/2015/05/9-1.pdf

Aldwin, C. M. (2007). Stress, coping, and development: An integrative perspective. New York, NY: Guilford Press.

Alexander, D. A., \& Klein, S. (2001). Ambulance personnel and critical incidents: Impact of accident and emergency work on mental health and emotional well-being. The British Journal of Psychiatry, 178(1), 76-81. doi:10.1192/bjp.178.1.76

Bennett, P., Williams, Y., Page, N., Hood, K., \& Woollard, M. (2004). Levels of mental health problems among UK emergency ambulance workers. Emergency Medicine Journal, 21(2), 235-236. doi:10.1136/emj.2003.005645

Brown, J., Mulhern, G., \& Joseph, S. (2002). Incident-related stressors, locus of control, coping, and psychological distress among firefighters in Northern Ireland. Journal of Traumatic Stress, 15(2), 161-168. doi:10.1023/A:1014816309959

Brown, J. M., \& Campbell, E. A. (1990). Sources of occupational stress in the police. Work \& Stress: An International Journal of Work, Health \& Organisations, 4(4), 305-318. doi:10.1080/02678379008256993

Bryant, R. A., \& Harvey, A.G. (1996). Posttraumatic stress reactions in volunteer 
firefighters. Journal of Traumatic Stress, 9(1), 51-62. doi:10.1002/jts.2490090106

Cheng, C., \& Cheung, M. L. (2005). Cognitive processes underlying coping flexibility: Differentiation and integration. Journal of Personality, 73(4), 859-886. doi:10.1111/j.1467-6494.2005.00331.x

DuBrin, A. J. (2013). Handbook of research on crisis leadership in organizations. Northampton, MA: Edward Elgar Publishing.

Hadley, C. N., Pittinsky, T. L., Sommer, S. A., \& Zhu, W. (2011). Measuring the efficacy of leaders to assess information and make decisions in a crisis: The C-LEAD scale. The Leadership Quarterly, 22(4), 633-648. doi:10.1016/j.leaqua.2011.05.005

Halpern, J., Gurevich, M., Schwartz, B., \& Brazeau, P. (2009). Interventions for critical incident stress in emergency medical services: a qualitative study. Stress and health, 25(2), 139149. doi:10.1002/smi.1230

Haus, M., Adler, C., \& Duschek, S. (in press). Crisis management organisations and (psychosocial) support. In J. Zelger \& J. Müller (Eds.), GABEK as a learning procedure for organizations. Innsbruck, Austria: Studienverlag.

Jensen, P. R., \& Wrisberg, C. A. (2014). Performance under acute stress: A qualitative study of soldiers' experiences of hand-to-hand combat. International Journal of Stress Management, 21(4), 406-423. doi:10.1037/a0037998

Karasek, R., \& Theorell, T. (1990). Healthy work: Stress, productivity, and the reconstruction of working life. New York, NY: Basic Books.

Kirkcaldy, B., Brown, J., \& Cooper, C. L. (1998). The demographics of occupational stress among police superintendents. Journal of Managerial Psychology, 13(1/2), 90-101. doi:10.1108/02683949810369156 
LaFauci-Schutt, J. M., \& Marotta, S. A. (2011). Personal and environmental predictors of posttraumatic stress in emergency management professionals. Psychological Trauma: Theory, Research, Practice, and Policy, 3(1), 8-15. doi:10.1037/a0020588

LeBlanc, V. R., Regehr, C., Birze, A., King, K., Scott, A. K., MacDonald, R., \& Tavares, W. (2011). The association between posttraumatic stress, coping, and acute stress responses in paramedics. Traumatology, 17(4), 10-16. doi:10.1177/1534765611429078

Liberman, A. M., Best, S. R., Metzler, T. J., Fagan, J. A., Weiss, D. S., \& Marmar, C. R. (2002). Routine occupational stress and psychological distress in police. Policing: An International Journal of Police Strategies \& Management, 25(2), 421-439. doi:10.1108/13639510210429446

Patterson, G. T. (2003). Examining the effects of coping and social support on work and life stress among police officers. Journal of Criminal Justice, 31, 215-226. doi:10.1016/S0047-2352(03)00003-5

Patterson, G. T., Chung, I. W., \& Swan, P. G. (2012). The effects of stress management interventions among police officers and recruits. Campbell Systematic Reviews, (7). Retrieved from http://www.campbellcollaboration.org/lib/project/150/

Pillai, R., \& Williams, E. A. (2004). Transformational leadership, self-efficacy, group cohesiveness, commitment, and performance. Journal of Organizational Change Management, 17(2), 144-159. doi:10.1108/09534810410530584

Regehr, C. \& Bober, T. (2005). In the line of fire. New York, NY: Oxford University Press.

Regehr, C., \& Millar, D. (2007). Situation critical: High demand, low control, and low support in paramedic organizations. Traumatology, 13(1), 49-58. doi:10.1177/1534765607299912 
Thompson, S. C. (1981). Will it hurt less if I can control it? A complex answer to a simple question. Psychological Bulletin, 90(1), 89-101.

Ungerer, D., \& Morgenroth, U. (2001). Analyse des menschlichen Fehlverhaltens in Gefahrensituationen - Empfehlungen für die Ausbildung. [Analysis of human error in hazardous situations - Recommendations for education.]. Zivilschutzforschung, 43. Bonn: Bundesverwaltungsamt-Zentralstelle für Zivilschutz.

Varker, T., \& Devilly, G. J. (2012). An analogue trial of inoculation/resilience training for emergency services personnel: Proof of concept. Journal of Anxiety Disorders, 26(6), 696-701. doi:10.1016/j.janxdis.2012.01.009

Young, P. M., Partington, S., Wetherell, M. A., St Clair Gibson, A., \& Partington, E. (2014). Stressors and coping strategies of UK firefighters during on-duty incidents. Stress and Health, 30(5), 366-376. doi:10.1002/smi.2616

Zelger, J. (2004). Qualitative research by the "GABEK®” method. In J. Fikfak, F. Adam, D. Garz (Eds.), Qualitative Research. (pp. 231-261). Ljubljana, Slovenia: ZRC Publishing. Zelger, J. (2014). WinRelan (Version 5.16) [Computer software]. Innsbruck, Austria: Zelger.

Notes:

[1] In this paper, the term crisis/disaster managers describes leaders, supervisors and authorities in crisis/disaster management (see definition in the participants section). The term crisis/disaster management personnel is used whenever first responders and crisis managers are referred to. [2] Three interviews were excluded from the analysis, two because they did not meet the criterion of direct involvement in the management of a major crisis, one because of missing data (i.e., relevant questions of the interview guideline were not answered). 
[3] When not deducible from the actual quote, the respective key terms coded in a text section are provided in square brackets.

[4] The alphanumerical code identifies the respective index card (containing one text section) in GABEK® WinRelan®.

[5] The network graph with the initial key term support has been previously presented in another publication, where parts of the data were analyzed in light of a different theoretical background (Haus, Adler, \& Duschek, in press). 